\title{
Conjoined twins with a horseshoe kidney
}

\section{Modi, MB BCh, FCRad (SA), MMed}

L Kramer, $M B$ BCh, FCRad (SA)

Department of Radiology, Chris Hani Baragwanath Hospital, University of the Witwatersrand, Johannesburg

\section{Abstract}

Conjoined twins are rare variants of monozygotic twins. There are many types of conjoined twins, usually classified according to the site of fusion. The most common type of renal fusion anomaly is the horseshoe kidney, comprising two distinct functioning kidneys on either side of the midline, which are more likely to be connected at the lower poles. We report on a 30-year-old woman who presented to the antenatal clinic at Chris Hani Baragwanath Hospital, Soweto. Fetal magnetic resonance imaging revealed thoraco-omphalopagus conjoined twins with complex thoracic and abdominal structures, including a horseshoe kidney that was confirmed on postnatal computed tomography screening. Our patient was classified as a thoraco-omphalopagus type, with fusion of the thorax and the mid-trunk.

\section{Introduction}

Conjoined twins are rare variants of monozygotic twins. They result from incomplete division of the embryonic disk. ${ }^{1}$ The incidence is estimated at about 1 in 250000 live births, with a strong female predominance. ${ }^{2}$ There are many types of conjoined twins, usually classified according to the site of fusion. The more common types of conjoined twins include the thoracopagus type where the fusion is anterior, at the chest, and involves the heart (35\%); the omphalopagus type where the fusion is at the mid-trunk (30\%); the pygopagus type where there is a posterior union involving the rump (19\%); the parapagus type, with a lateral fusion of the lower half of the body extending upwards (5\%); and combination types. Our patient was classified as a thoraco-omphalopagus type, with fusion of the thorax and the mid-trunk. ${ }^{3}$

The most commonly described type of renal fusion anomaly is the horseshoe kidney. It consists of two distinct functioning kidneys on either side of the midline, which are more likely to be connected at the lower poles by an isthmus of functioning renal parenchyma or fibrous tissue that crosses the midline of the body. ${ }^{4}$ The reported frequency of horseshoe kidney ranges from 1 in 400 live births to 1 in 800 live births, and is twice as common in males as in females. There is no known genetic determinant, although it has been reported in siblings and in identical twins in the same family. ${ }^{4}$

\section{Case report}

A 30-year-old woman presented to the antenatal clinic at Chris Hani Baragwanath Hospital, Soweto, at $>34$ weeks' gestation. She had been referred from a peripheral hospital. An ultrasound examination revealed probable thoraco-omphalopagus conjoined twins and polyhydramnios.

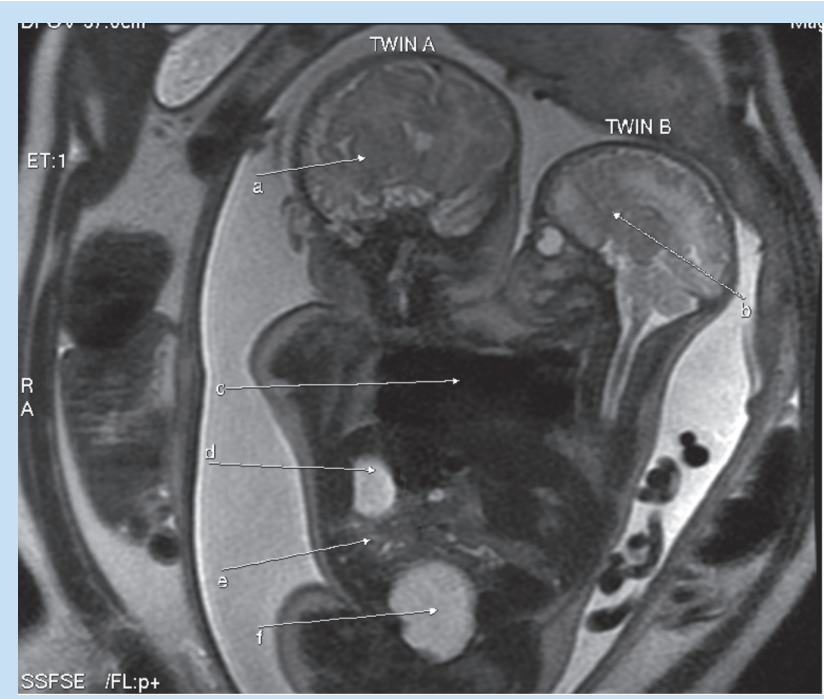

Fig. 1. Coronal T2-weighted MRI.

a: brain of twin A demonstrating mature grey-white matter differentiation

b: twin $B$ on the right in a sagital position looking at twin $A$

$c$ : the complex multi-chambered heart

d: stomach of twin A

e: horseshoe kidney

f: high signal in the pelvis due to a single full bladder.

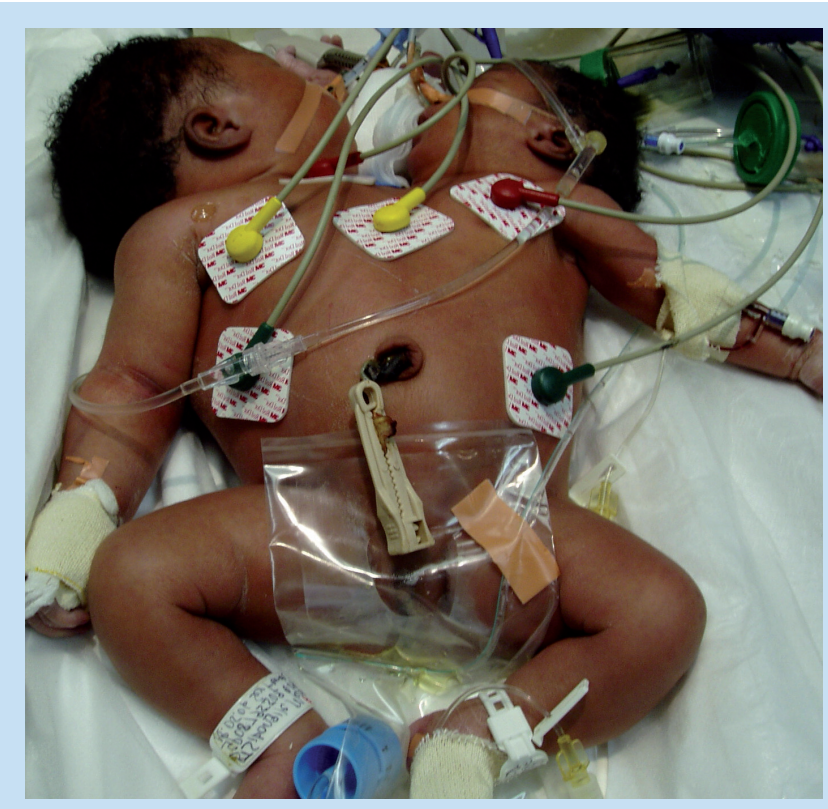

Fig 2. Day 2 post delivery photograph showing the larger twin $A$ on the left, smaller twin $B$ on the right, 2 heads, 2 necks, extra-large conjoined thorax, 2 sets of upper limbs, single female genitalia, and single set of lower limbs

However, the exact details of the fusion were not fully elucidated.

Fetal magnetic resonance imaging (FMRI) was performed on a General Electric 1.5 tesla MR scanner using a phased-array pelvic coil. T1-weighted and T2-weighted images were obtained in 2 orthogonal 


\section{CASE REPORT}

planes only, as the mother was uncomfortable. The FMRI demonstrated a larger dominant 'twin A' and a smaller 'twin B'. Two heads, 2 sets of upper limbs, 2 complete spines, a single complex multi-chambered heart, a conjoined liver, a single gallbladder, 2 stomachs, a long horizontally positioned centrally fused shared kidney, an additional single kidney in twin B, a single urinary bladder, a single bony pelvis, and a single set of lower limbs were seen. Twin B also had a hyploplastic right lung, and an aplastic left lung (Fig. 1).

The mother was counselled about the poor prognosis for conjoined thoraco-omphalopagus twins; however, she opted not to have the pregnancy terminated and the twins were delivered by caesarean section 3 days later (Fig. 2). After delivery, on day 2, a whole-body contrast-volume computed tomography (CT) scan was performed using a Toshiba 4-slice multidetector CT scanner to further assess the anatomy of the twins, and to evaluate them for viability and separability. The scan confirmed a centrally positioned horseshoe kidney in twin A, and a single kidney in twin B, where the renal hilum was posterolateral because of the abnormal renal axis (Fig. 3). The twins died on day 3.

\section{Conclusion}

To our knowledge, this is the first reported case of a shared horseshoe kidney in thoraco-omphalopagus twins.

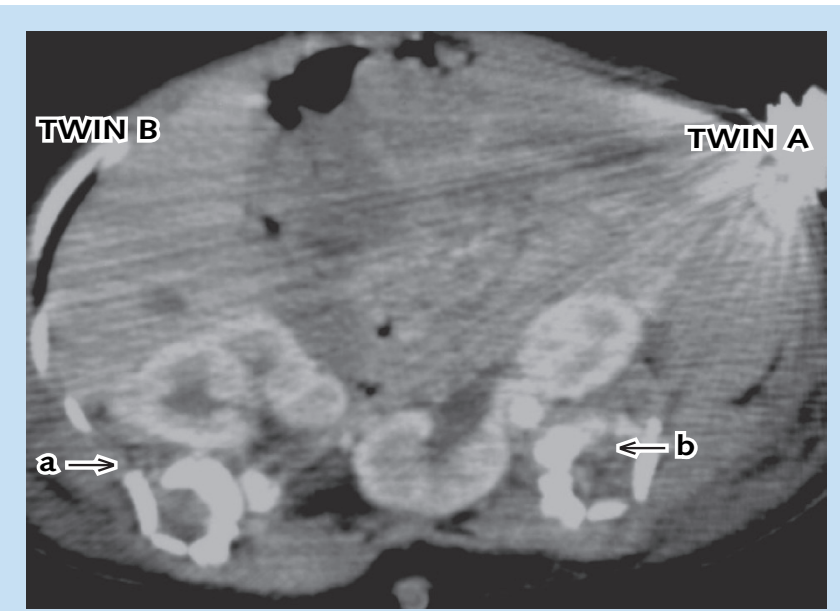

Fig 3. Axial post-contrast CT of the abdomen.

a. Twin $B$ - single kidney with abnormal renal axis.

b. Twin A - central horseshoe kidney with a ventral collecting system.

1. Khanna PC, Pungavkar SA, Patkar DP. Ultrafast magnetic resonance imaging of cephalothoracopagu janiceps disymmetros. J Postgrad Med 2005; 51: 228-229.

2. Mchugh K, Kiely EM, Spitz L. Imaging of conjoined twins. Pediatr Radiol 2006; 36(9): 899-910.

3. Types of conjoined twins. http://zygote.swarthmore.edu/cleave4a.html (accessed 15 July 2006).

4. Allen RC. Horseshoe kidney. http://emedicine.medscape.com/article/441510-overview (accessed 16

February 2009). 